\title{
Linguagem, NTIC e a sala de aula: o que propõem as pesquisas de intervenção
}

Language, ICT and the Classroom: What Interventional Researches Propose

\author{
Núbio Delanne Ferraz Mafra* \\ Universidade Estadual de Londrina \\ Londrina - Paraná / Brasil \\ Carla Viana Coscarelli** \\ Universidade Federal de Minas Gerais \\ Belo Horizonte - Minas Gerais / Brasil
}

\begin{abstract}
RESUMO: Desenvolveu-se uma análise de aspectos de linguagem e novas tecnologias de informação e comunicação (NTIC) nas teses e dissertaçôes de caráter interventivo em sala de aula de Língua Portuguesa, produzidas entre 2000 e 2010 nos programas de pós-graduação nacionais de Letras e Linguística. Para este artigo, foram abordadas as concepçôes de linguagem e de aprendizagem, os blogs de turma e o destaque dado a eles nos estudos, além do perfil e lugar dessas pesquisas de intervenção no âmbito da Linguística Aplicada. Ao final, com base nesses aspectos, procurou-se apresentar não só um balanço da produção no referido período, como também sinalizar desafios para as futuras ações e pesquisas em Linguística Aplicada nesse campo.
\end{abstract}

PALAVRAS-CHAVE: letramento digital; teses e dissertaçôes; concepções de linguagem e de aprendizagem; ensino de Língua Portuguesa.

ABSTRACT: We developed an analysis of linguistic aspects and of how information and communication technology (ICT) was treated in theses and dissertations that deal with interventional research in Portuguese language classes, produced between 2000 and 2012 in national post-graduation programs of Language and Linguistics. We discuss here conceptions of language and learning adopted by the researches, the emphasis they give to class blogs and the features and place of these interventional researches in the scope of Applied Linguistics. Finally, based on these aspects, we tried to present not only a balance of the production in that period, but signaling as well challenges for future actions and research in Applied Linguistics in this field. KEYWORDS: digital literacy; theses e dissertations; language and learning conceptions; Portuguese language teaching.

\footnotetext{
*nubiomafra@yahoo.com.br

**cvcosc@yahoo.com.br
} 
E eu pergunto: com que roupa?

Com que roupa que eu vou

Pro samba que você me convidou?

Noel Rosa

Quais as concepções de linguagem e de aprendizagem presentes em teses e dissertações produzidas na última década, relacionadas ao letramento digital no ensino de Língua Portuguesa? Que caminhos devem trilhar futuras pesquisas e ações docentes e de quais caminhos os professores devem se desviar, tendo em vista um trabalho eficiente e fundamentado no âmbito do letramento digital? Questôes como essas nos moveram a analisar as teses e dissertações sobre o tema, produzidas entre 2000 e 2010 nos programas de pós-graduação nacionais de Letras e Linguística. ${ }^{1}$

Neste texto, procuraremos primeiramente analisar as concepções de linguagem e de aprendizagem em Língua Portuguesa que têm fundamentado a atuação do professor em sala de aula. Na sequência, sinalizaremos os desafios postos a essas concepçóes em contextos contemporâneos de letramento digital. A detalhada apresentação do corpus investigado precede a análise de alguns aspectos tanto no âmbito do ensino de Língua Portuguesa, com destaque para as referidas concepçôes de linguagem e de aprendizagem, quanto no âmbito específico da pesquisa científica, na reflexão sobre o perfil e o lugar das pesquisas de intervenção no âmbito da Linguística Aplicada.

\section{Concepções de linguagem e de aprendizagem em contextos de letramento digital}

As décadas de 1980 e 1990, embaladas pelo processo de rediscussão nacional das questões básicas e estruturantes da Educação em nosso país, foram pródigas em trabalhos que refletiram sobre as concepções de linguagem e de aprendizagem de Língua Portuguesa. No âmbito das concepções de linguagem, destacamos Geraldi (1984), Travaglia (1996) e Soares (1998). Partindo da análise do subjetivismo idealista, do objetivismo abstrato e da concepção dialógica de linguagem, aqueles estudos identificaram, em linhas gerais, três concepçôes de linguagem: como expressão do pensamento, como instrumento de comunicação e como forma de interação.

${ }^{1}$ Pesquisa com o apoio financeiro da Fundação Araucária (Edital 16/2011). 
Essas concepções de linguagem se articularam ao universo do ensino de línguas em nosso país, em especial ao ensino de Língua Portuguesa, inspirando até hoje vários documentos oficiais em diferentes instâncias governamentais e níveis de ensino, no âmbito da educação básica e da formação de professores. Nesse contexto, a concepção bakhtiniana ${ }^{2}$ de linguagem como interação, com destaque para o sujeito do discurso, cresceu sobremaneira no campo da metodologia e didática da Língua Portuguesa, alterando inclusive paradigmas conceituais.

A presença mais sistematizada e crescente das novas tecnologias de informação e comunicação (NTIC) no cotidiano social, a partir da década de 1990, possibilitou que a comunicação entre as pessoas acontecesse em outras formas de manifestação, como as que eclodiram na internet, a exemplo das diversas redes sociais. Isso aconteceu devido à dimensão de produção de conteúdo, interação e compartilhamento por parte dos usuários, possibilitada pela Web 2.0. Nesse particular, destoando de alguns teóricos que veem as NTIC como uma ruptura em relação às concepções e linguagem vigentes, Buzato (2007) identifica, ao contrário, o hibridismo como marca da linguagem digital.

Não estou negando que as diferenças entre oral e escrito, ou entre impresso e digital existam, ou mesmo sugerindo que todas as análises centradas na explicitação dessas diferenças sejam desprovidas de valor. Muito ao contrário, creio que é normalmente pela via do contraste que se pode melhor perceber onde estão as convergências e as apropriações mútuas. Contudo, até onde possamos crer em homologias, o potencial inclusivo/ exclusivo da linguagem digital não está naquilo que a afasta ou aproxima do impresso ou do natural, do verbal ou do visual, mas nas maneiras como faz integrarem-se ou agenciarem-se mutuamente esses códigos, modalidades, tecnologias e usos de linguagem. (BUZATO, 2007, f. 79).

As concepções de aprendizagem naturalmente se articulam ao seu histórico de transformações, expressando hoje prática de docência menos como locus do saber e mais como mediação, cooperação e compartilhamento; situações mais naturais e espontâneas de uso da linguagem; articulação dos saberes escolarizados aos saberes sociais mais amplos e dimensão mais ativa e participativa do aluno na construção dos saberes em sala de aula, dentre outros aspectos.

Analisando os "amaldiçoados" videogames, Gee (2009) identifica neles alguns importantes princípios a serem levados em conta na aprendizagem

\footnotetext{
${ }^{2}$ Neste texto, o adjetivo bakhtiniana e suas variantes relacionam-se ao conjunto da produção atribuída ao Círculo de Bakhtin.
} 
contemporânea. Dentre eles, destacamos: identidade, interação, produção, desafios, ordenação de problemas, customização e pensamento lateral. Vale observar que Gee "bebe" das fontes dialógicas e sociointerativas, mas as enriquece, integrando suas concepções de aprendizagem a teorias atuais de caráter cognitivo e antropológico.

Todo esse histórico de transformações no âmbito das concepções de linguagem e de aprendizagem infelizmente ainda repercute muito pouco no cotidiano de sala de aula. Em tempos de desafios relacionados ao letramento digital, o cenário mais comum que encontramos ainda é a aula de Língua Portuguesa ser tratada como sinônimo único e exclusivo de ensino de gramática normativa.

\section{Linguagens, NTIC e a sala de aula}

Recente pesquisa da Fundação Telefônica Vivo, denominada Geraçôes interativas Brasil: crianças e jovens diante das telas, mostra que três em cada quatro adolescentes navegam na internet; porém, 40\% dizem que professores não usam a Web na escola (CASTRO; ALMEIDA, 2012). Vejamos outros números dessa pesquisa:

\begin{tabular}{|c|c|c|}
\hline & Crianças (6-9 anos) & Adolescentes (10-18 anos) \\
\hline Usam computador & $51,0 \%$ & $60,0 \%$ \\
\hline Possuem celular & $38,8 \%$ & $74,7 \%$ \\
\hline Jogam videogame & $62,4 \%$ & $78,7 \%$ \\
\hline \multicolumn{3}{|c|}{$\begin{array}{l}\text { 64,2\% aprenderam a usar a internet sozinhos } \\
32,0 \% \text { dos pais não vigiam a navegação dos filhos } \\
53,0 \% \text { dos adolescentes usam a internet para estudar e fazer o dever de casa } \\
34,5 \% \text { nunca se desligam da internet, nem durante a aula }\end{array}$} \\
\hline
\end{tabular}

Fonte: Elaboração própria

FIGURA 1 - Dados da pesquisa Gerações Interativas Brasil

Com base nesse cenário, na condição de pesquisadores no âmbito do letramento digital, somos constantemente contatados para "ensinar" licenciandos em Letras e professores em diferentes níveis de formação a "trabalhar" com as novas tecnologias em sala de aula. Outras vezes, colegas de departamento nos vêm solicitar ajuda, com a frase se iniciando por "Você, que 
entende dessas coisas de letramento digital...”. Nesse último caso, a solicitação completa pode ser desde uma palestra até a resolução de um problema técnico no computador.

As aspas aqui apresentadas sinalizam contextos de produção e efeitos de sentido subjacentes a elas que demandam explicitação. Ao mesmo tempo, espera-se que a explicitação desses contextos e sentidos contribua para melhor situar o conceito de letramento digital e dos nossos lugares - de pesquisadores, licenciandos e professores - nesse cenário.

O "ensinar", nesse contexto, pode inicialmente denotar a existência de um conhecimento em lugar acessível ao pesquisador e, por extensão, inacessível ao licenciando e professor. Esse talvez seja o primeiro equívoco sobre letramento digital e que, ao mesmo tempo, pode contribuir no processo de compreensão do conceito. Desse ângulo da questão, aproximamo-nos de Street quando ele afirma que "[l] etramento digital está no meio do debate neste momento. Gosto de usar o termo, desde que não signifique que a tecnologia está determinando a prática. É sempre ao contrário: as práticas sociais determinam como usamos a tecnologia” (STREET, 2010, p. 45).

O letramento digital não está, portanto, localizado numa instância totêmica, mas ordinariamente entranhado em diferentes práticas sociais. Por isso mesmo, essa forma de letramento está aprioristicamente acessível a todos que militam no ensino, porquanto não é às NTIC que devemos nos dirigir, mas às demandas que a sociedade constrói para fins de utilização desses recursos digitais. Infelizmente, no que compete aos cursos de formação, eles ainda não se deram efetiva conta dessa constante e crescente demanda, presente de forma significativa a partir da década de 1990 no Brasil.

Em Mafra e Moreira (2012), recuperou-se o histórico, ainda que breve, de compreensão dos perfis e formas de atuação do professor de Língua Portuguesa no âmbito do letramento digital. Nesse histórico, o professor é apresentado na década de 1990 como perplexo perante as NTIC. Já na década de 2000, os professores de Língua Portuguesa são apresentados perante três obstáculos a serem superados na sua relação com as novas práticas possibilitadas pela cibercultura: medo, incapacidade no domínio técnico e ausência de processo reflexivo sobre a tecnologia. Atualmente, os resultados da pesquisa desenvolvida (MAFRA; MOREIRA, 2012) apontam para relações menos pessimistas entre professores e NTIC do que as identificadas em décadas anteriores. Na referida pesquisa, os professores declaram conhecer os recursos básicos do computador, declaram saber acessar à internet, administrar o envio 
e recebimento de e-mails, produzir apresentações em PowerPoint, por exemplo, mas externam a carência de uma melhor formação que articule esse conhecimento básico a uma renovada dimensão do ensino de Língua Portuguesa: seriam hoje, portanto, semiletrados em busca de um letramento digital pleno.

Com base nessa identificação de perfis e forma de atuação do docente de Língua Portuguesa na esfera do letramento digital - e na constatação de suas atuais demandas -, entendemos que o mapeamento de investigaçōes que tenham atuado interventivamente na esfera didático-pedagógica das salas de aula do ensino fundamental e médio contribuiria, num primeiro momento, para uma ampla visualização e análise do cenário de pesquisas desenvolvidas, colaborando assim numa ação mais consistente voltada para as demandas do professor de Língua Portuguesa, ora identificadas.

É muito importante, nesse momento em que tecnologias digitais estão se instalando em nossa sociedade, conhecer experiências práticas que lidam com as NTIC em ambientes de ensino de Língua Portuguesa, para que elas sirvam de referência para uma proposta de uso efetivo dessas tecnologias como recurso pedagógico. Esse é um saber que está sendo construído e as experiências precisam ser compartilhadas e analisadas a fim de compor uma massa crítica.

A indagação que fica agora é que concepções de linguagem e de aprendizagem fundamentam o conjunto das 29 teses e dissertaçôes, e com que abordagens metodológicas elas trabalham. É o que procuraremos avaliar na sequência.

\section{A seleção do corpus}

Essa investigação partiu da pesquisa nacional do Grupo de Trabalho (GT) Linguagens e Tecnologias da Associação Nacional de Pós-Graduação e Pesquisa em Letras e Linguística (ANPOLL), do qual participamos, que fez o levantamento das teses e dissertações produzidas nos programas de pósgraduação da área de Letras e Linguística no país (classificação CAPES) sobre linguagens e NTIC no período 2000-2010. Com membros do GT, docentes de diferentes instituições de ensino superior no país, coletamos dados das nossas respectivas instituições e/ou dos estados de origem.

Porém, ao final da etapa, constatou-se que muitas instituições e/ou estados não haviam sido contemplados com o levantamento. O pleno levantamento nacional das informações era imprescindível não só ao desenvolvimento da pesquisa do GT como à pesquisa que iniciávamos 
referente a estágio de pós-doutoramento. Nesses termos, empenhamo-nos pessoalmente para o levantamento das informações que faltavam. Ao todo, procedeu-se ao levantamento de 460 teses e dissertaçóes.

A partir do levantamento de teses e dissertações feitos nos programas de pós-graduação da área de Letras e Linguística no país (classificação CAPES) sobre linguagens e novas tecnologias de informação e comunicação buscamos analisar o recorte específico da nossa investigação: trabalhos voltados para $o$ caráter de pesquisa de intervenção no ensino presencial de Lingua Portuguesa na educação básica. Para o desenvolvimento da análise, essa expressão definidora do nosso objeto de interesse representou cinco sub-recortes para fins de identificação, apresentados no quadro a seguir como parâmetros de classificação:

\begin{tabular}{|ccc|}
\hline \multicolumn{3}{|c}{ PARÂMETROS DE CLASSIFICAÇÃO } \\
\hline P1 & ensino formal ou formação de professores & ENS/NENS \\
\hline P2 & presencial & PRE/NPRE \\
P3 & educação básica (ensino) & EDB/NEDB \\
\hline P4 & língua portuguesa/literatura & LPO/NLPO \\
P5 & intervenção & INT/NINT
\end{tabular}

Fonte: Elaboração própria.

FIGURA 2 - Parâmetros de classificação

$\mathrm{Na}$ terceira coluna do quadro, constam duas classificações para cada um dos parâmetros, separadas por uma barra. A segunda classificação, após a barra, expressa ausência/oposição da identificação buscada, sempre iniciada pela letra N. Em P1, por exemplo, "NENS" significa "não voltado para o ensino formal ou formação de professores".

No percurso dessa análise, algumas interessantes constatações começaram a surgir. A primeira delas é a expressiva presença de trabalhos voltados para outras áreas que não o ensino. $\mathrm{Na}$ área educacional, a grande maioria das pesquisas é voltada para o ensino de língua estrangeira, principalmente o Inglês, e para a modalidade a distância. Apesar de essas constatações colaborarem de alguma forma para a constituição do recorte que 
buscávamos, não iremos nos debruçar detidamente sobre elas neste artigo, por não estarem diretamente relacionadas ao foco que pretendemos dar a esta pesquisa, que é o ensino de Língua Portuguesa presencial. De qualquer forma, é importante deixar registrada nossa preocupação com o proporcionalmente reduzido número de pesquisas voltadas para o ensino presencial de Língua Portuguesa articulado às NTIC.

Do referido universo de 460 teses e dissertações, identificamos apenas 41 pesquisas dentro do nosso recorte de análise, sendo que, posteriormente, após uma análise mais acurada dos documentos e, principalmente, das possibilidades de acesso a ele - somente trabalhos que contivessem textos na íntegra disponibilizados principalmente no site das instituiçóes, já que no caso de alguns apenas foram encontrados o título ou o resumo -, essa seleção viuse reduzida a 29 trabalhos (6,3\% do total).

Apresentamos a seguir as 29 teses e dissertações, ordenadas por ano de defesa e ordem alfabética de autoria, respectivamente:

\section{QUADRO 1}

Seleção final de pesquisas voltadas para o ensino presencial de Língua Portuguesa articulado às NTIC

T01 Clarmi Regis. O texto no espaço virtual: a leitura em rede. Dissertação. Literatura, UFSC, 2002.

T02 Fabiana Macedo Fausto. O leitor e o texto multimodal: aspectos afetivos e cognitivos. Dissertação. Interdisciplinar Linguística Aplicada, UFRJ, 2006.

T03 Jaqueline de Quadros Barbosa. O ato de ler como prática social: a "arqui-leitura" de um cederrom. Dissertação. Literatura, UFSC, 2006.

T04 Milena Pereira Mendes. Novas tecnologias, novas leituras e conscientização literária. Dissertação. Interdisciplinar Linguística Aplicada, UFRJ, 2006.

T05 Tiago da Silva Ribeiro. Internetês: abreviaturas e outras estratégias de leitura. Dissertação. Letras, PUC-Rio, 2006.

T06 Valéria Maria Cavalcanti Tavares. Ensino de leitura do hipertexto: um estudo sobre a preparação de atividades instrucionais em Inglês e Português, em escolas de Fortaleza. Dissertação. Linguística Aplicada, UECE, 2006.

T07 Vanessa Doumid Damasceno. Ojogo digital nos processos de ensino aprendizagem de língua portuguesa: um estudo através das sequências narrativas. Dissertação. Linguística Aplicada, Unisinos, 2006.

T08 Cristina de Matos Martins. Um estudo do perfil textual de role playing games 'pedagógicos'. Dissertação. Filologia e Língua Portuguesa, USP, 2007. 
T09 Evaristo Ferreira Vilha. Ressignificando linguagens no espaço escolar: esboçando um outro mapa para leitura e escrita de textos. Dissertação. Letras, UNIOESTE, 2007.

T10 Marcio Antonio de Moraes. A produção do gênero dissertativo: reflexóes sobre o uso da internet na escola. Dissertação. Linguística Aplicada, Unicamp, 2007.

T11 Silvia Helena Firmino Zanutto. Hipermídia: novo formato para o conhecimento. Dissertação. Letras, UPM, 2007.

T12 Andréia Vielmo de Quadros. Interatividade na produção e manutenção de um site educacional. Dissertação. Linguística Aplicada, Unisinos, 2008.

T13 Cláudia Cristina Gatti Félis. Interação na internet: os blogs como uma nova forma de usar a linguagem. Dissertação. Estudos da Linguagem, UEL, 2008.

T14 Cláudia Rodrigues. O uso de blogs como estratégia motivadora para o ensino de escrita na escola. Dissertação. Linguística Aplicada, Unicamp, 2008.

T15 Marcelo Cafiero Dias. A influência do modo de organização de hipertextos na compreensão. Dissertação. Estudos Linguísticos, UFMG, 2008.

T16 Paulo de Tarso Roma de Oliveira. Expressão de opinião de adolescentes em bate-papos e redaçôes escolares: um estudo sob a ótica da avaliatividade. Dissertação. Linguística Aplicada e Estudos da Linguagem, PUC-SP, 2008.

T17 Gilse Cabrera Rissi. Hipertexto e estratégias de leitura. Dissertação. Língua Portuguesa, PUC-SP, 2009.

T18 Jaqueline de Moraes Fiorelli. Práticas de letramento na rede: ações discursivas, agência e o papel do outro na construção da autoria. Tese. Filologia e Língua Portuguesa, USP, 2009.

T19 Margarida Maria Calafate dos Santos. As novas tecnologias em projetos interdisciplinares na escola pública: um estudo à luz da Teoria da Atividade. Dissertação. Interdisciplinar Linguística Aplicada, UFRJ, 2009.

T20 Maria Margareth Pereira. Relaçôes midiáticas: do blog a uma (re)leitura da escrita na construção da aprendizagem. Dissertação. Linguística Aplicada, UNITAU, 2009.

T21 Raquel Freitas Sampaio. O uso da hipermídia como recurso didático para o ensino de poesia no ensino médio. Dissertação. Letras, UPM, 2009.

T22 Sávio Antônio Pereira. A produção escrita em língua materna, no ensino médio, nas interfaces papel e blog: caracterização e coesão. Dissertação. Linguística Aplicada e Estudos da Linguagem, PUC-SP, 2009.

T23 Valdeci Maria de Oliveira Coelho Barbosa. Gêneros digitais em manuais didáticos de língua portuguesa. Dissertação. Língua Portuguesa, PUC-SP, 2009.

T24 Vanessa Lacerda da Silva. O uso do computador como instrumento de leitura para aquisição do conhecimento: um estudo de caso. Dissertação. Letras, UERJ, 2009.

T25 Carmen Pimentel. Blog: da internet à sala de aula. Tese. Letras, UERJ, 2010. 
T26 Lidia Helena Muller Zart. A escrita emergente: autoria nas produçôes textuais escolares em ambientes digitais, com o uso da internet. Dissertação. Linguística Aplicada, Unisinos, 2010.

T27 Mariana Ribeiro de Carvalho Camolese. Estudo sobre as produções de texto de alunos do ensino fundamental: a influência da internet. Dissertação. Linguística, UFSCar, 2010.

T28 Mariane Rocha Silveira. Blog: eu te lendo e eu te escrevendo. Dissertação. Letras, UPF, 2010.

T29 Tereza Cristina Moraes do Nascimento. Análise da aplicação de um hipertexto com alunos do ensino médio. Dissertação. Interdisciplinar Linguística Aplicada, UFRJ, 2010.

Fonte: Elaboração própria.

Se pensarmos na organização clássica das disciplinas de Letras na educação básica em Língua Portuguesa e Literatura e no nível de ensino, as teses e dissertações analisadas se voltam para o seguinte contexto: ${ }^{3}$

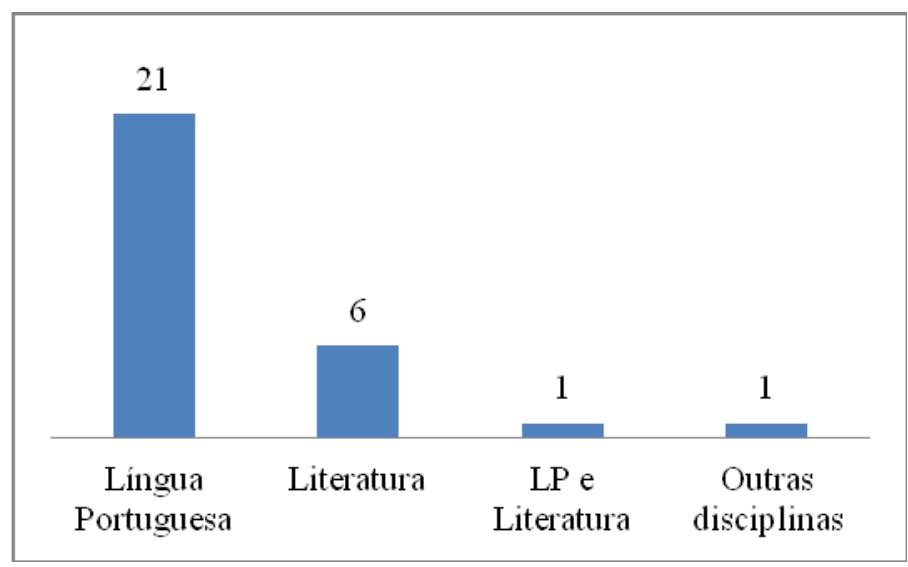

GRÁFICO 1 - Disciplinas de Letras na educação básica Fonte: Elaboração própria.

${ }^{3}$ No GRÁFICO 1, ao utilizarmos a expressão outras disciplinas, referimo-nos à pesquisa T19, de caráter interdisciplinar, em que a disciplina Língua Portuguesa era campo de estudo, dentre outras disciplinas da educação básica. 


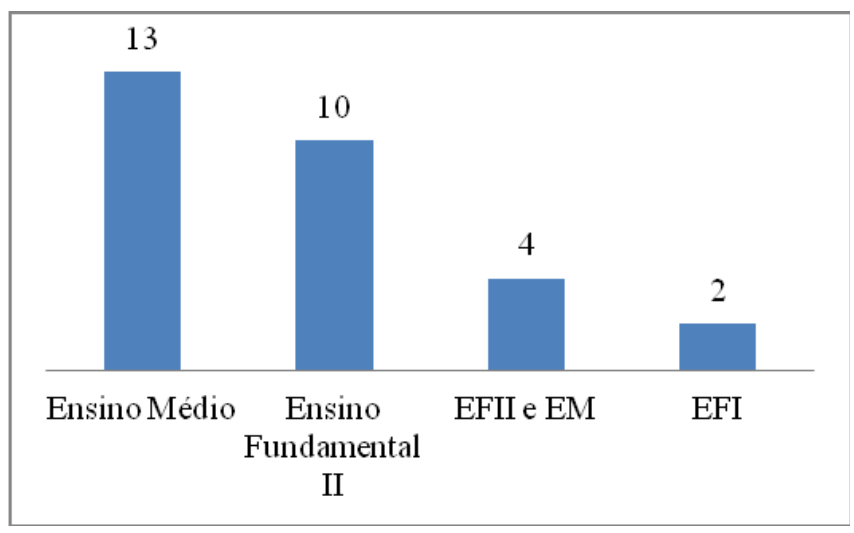

GRÁFICO 2 - Níveis de ensino

Fonte: Elaboração própria.

Pretende-se então, neste texto, apresentar resultados da análise de um conjunto de elementos dessas 29 teses e dissertaçôes - voltadas para o caráter de pesquisa de intervenção no ensino presencial de Língua Portuguesa na educação básica - que buscou identificar recorrências que contribuam para a construção de caminhos investigativos futuros no âmbito do letramento digital em Língua Portuguesa. Sendo assim, serão apresentados a seguir alguns resultados encontrados nessas análises, que são: a recorrência de fundamentação teórica dos trabalhos pautada nas concepções bakhtinianas de linguagem; a recorrência da criação de blogs da turma; a necessidade que encontramos de ampliar o conceito de pesquisa de intervenção.

\section{Das concepções bakhtinianas de linguagem}

Hoje já é consenso que as linhas gerais das concepções de linguagem adotadas levam em conta aspectos sociais, interacionais e/ou dialógicos calcados em visões inter, trans ou multidisciplinares. Nesse cenário, a produção do Círculo de Bakhtin ganha destaque, sendo explicitamente citada em catorze trabalhos voltados para o ensino de Língua Portuguesa (T07, T09, T10, T13, T16, T17, T18, T20, T22, T23, T24, T25, T26, T27) -, sendo que a produção do círculo é base da fundamentação em boa parte destes trabalhos. Em sete outras pesquisas voltadas para o ensino de Língua Portuguesa (T05, T06, T12, T14, T15, T28, T29), apesar de não haver referência à produção desse círculo, ela indiretamente se faz presente em função da reconhecida filiação, dos autores elencados nessas pesquisas, às concepções bakhtinianas. 
É natural que a produção do Círculo de Bakhtin não se faça presente de forma tão incisiva nos trabalhos voltados para o ensino de Literatura, dadas as especificidades consideradas por essa área de conhecimento. Mesmo assim, constatamos em duas das sete pesquisas na área (T01, T21) uma referência explícita a Bakhtin, ainda que numa obra mais diretamente atinente às discussões literárias: "Questôes de literatura e de estética: a teoria do romance". Características inter, trans ou multidisciplinares das pesquisas aparecem, ainda que de forma tímida e subentendida, em muitos trabalhos. Quando ocorre a explicitação dessas características, elas costumam estar associadas à área da Linguística Aplicada (T10, T19).

Portanto, a análise das concepçôes de linguagem das teses e dissertaçôes sobre ensino presencial na educação básica de Língua Portuguesa (num sentido amplo, incluindo a Literatura), produzidas de 2000 a $2010 \mathrm{em}$ programas de pós-graduação de Letras/Linguística, indicam uma uniformidade e coerência na contextualização e nos encaminhamentos teóricos.

Ao mesmo tempo, a recorrência à produção bakhtiniana - e, por que não dizer, vigotskyana - leva muitas vezes a uma entronização desses estudos clássicos no campo da linguagem de caráter sociointeracionista e dialógica, sinalizando uma cristalização da produção nesse campo. Essa cristalização desconsidera um sólido conjunto de estudos posteriores e atuais que, levando em conta os trabalhos seminais, têm procurado avançar na compreensão das características e das potencialidades da linguagem em articulação com as NTIC.

Ao situarmos a discussão especificamente na esfera do ensino, constatamos que a coerência na abordagem teórica das concepções de linguagem nas teses e dissertaçōes produzidas na última década muito contribuiu para uma consolidação primeira das discussōes relacionadas às NTIC na grande área de Letras/Linguística. Porém, na caminhada a ser empreendida nesta e nas próximas décadas, mais do que um problema, vemonos perante uma grande encruzilhada. Na busca do melhor caminho, nossos olhares e lentes são suficientes?

Existem muitos aspectos relacionados às NTIC sobre os quais precisamos refletir, como, por exemplo, a questão dos novos letramentos (NEW LONDON GROUP, 1996), da multimodalidade (KRESS; VAN LEEUWEN, 1996), dos multiletramentos (COPE; KALANTZIS, 2000; ROJO, 2009) das agências de letramento (STREET, 1984; 2010, BAZERMAN, 2006), das concepçóes de aprendizagem que dão ao aprendiz um papel mais ativo e reforçam a necessidade de uma postura crítica frente a esse processo (ANDREOTTI; SOUZA, 2011), 
das questões relacionadas à produção (BRUNS, 2008) à interatividade (PRIMO, 2007; SILVA, 2002), entre outras. Esse é um referencial teórico que avança nas discussões sobre letramento e sobre aprendizagem que não foi incorporado à maioria dos trabalhos.

Trata-se, sabemos, de uma pergunta arriscada, porquanto sacode as estruturas de um saber científico clássico, que se pretende "coerente" e "articulado". Em maior ou menor grau, é fato que a grande maioria das teses e dissertaçōes analisadas, conforme expusemos, representa esse perfil de saber, transitando nas áreas de conhecimento compreendidas como necessárias à investigação proposta e, eventualmente, "flertando" aqui e ali com outras fronteiras e limites. Mas é igualmente fato que, passada uma década de pesquisas no âmbito do letramento digital, pouco ou quase nada se alterou nos cotidianos, saberes e fazeres das aulas de Língua Portuguesa.

\section{Da criação de blogs da turma}

Cotidianos, saberes e fazeres das aulas... o que são? Como se processam? O que joga a linguagem nesses contextos, para além deles e a eles articulados? Analisando pesquisas desenvolvidas, fica-nos a impressão de que, de posse de uma "roupa" minimamente adequada, falta-nos agora "cair no samba". Mas um samba diferente, temperado pelas práticas sociais de letramento articuladas às NTIC, deslocando quadris, mesas, mas principalmente lugares institucionalizados dos saberes. Samba para dançar, pensar e fazer junto, interagindo, em compartilhamento.

Nessa aproximação da sala de aula de Língua Portuguesa com o cotidiano atual, a reflexão científica na grande área de Letras/Linguística é fundamental, mas na maioria dos casos tem se demonstrado insuficiente para a consolidação de determinadas práticas. Felizmente outros pesquisadores também têm enxergado essa insuficiência.

Assim, na discussão sobre nossa formação, também a equipe de pesquisa reviu alguns de seus supostos sobre as capacidades do professor:

a) em que pese a satisfação que temos todos (eles e nós) na aprendizagem de novas arquiteturas linguísticas e discursivas ou mesmo de construtos das teorias da aprendizagem, isso não nos ensina a ensinar;

b) a questão didática, no caso de um linguista aplicado, deverá ser muito mais seriamente levada em conta, embora essa seja uma de nossas áreas adjetivas e não a substância de nossa formação. (ROJO, 2008, p. 333-334). 
No caso de pesquisas com blogs, bastante presentes no período investigado (T13, T14, T20, T22, T25 e T28) - e por isso, focalizados neste artigo -, muitas delas propuseram, de forma oportuna, por exemplo, a criação de blogs da turma, feitos pelos alunos. Ocorre que a maioria desses blogs esteve em atividade enquanto durou a pesquisa de mestrado ou doutorado; terminada a pesquisa, as postagens pararam (como é o caso de T14 e T28).

Se pensarmos que todas essas pesquisas sobre $b \log$ foram produzidas com um delay médio de dois anos, talvez se justifique essa preponderância no período 2000-2010. Com o recente fortalecimento de redes sociais como o Facebook, em que os processos interativos se fazem de forma mais frequente e dinâmica, os blogs têm experimentado um relativo ostracismo na internet, mas continuam motivando investigações acadêmicas voltadas para a sala de aula. Pelo mesmo motivo desse delay, quase não se veem ainda pesquisas sobre redes sociais - lembrando que o Orkut surgiu, cresceu e praticamente desapareceu nesse recente espaço de tempo.

$\mathrm{O}$ uso de blogs foi e ainda tem sido feito de forma incipiente como recurso didático, ou seja, o blog assume o papel de um "mural digital", lugar em que os alunos postam as atividades que desenvolveram. Esse uso dos blogs tem como pontos positivos, entre outros, colocar o aluno em contato com os ambientes digitais e convencê-lo de que ele pode ser autor e produtor de materiais que podem ser vistos e comentados por muitas pessoas. Por outro lado, é possível notar que, nos casos analisados, o blog não foi incorporado pela escola como uma atividade comunicativa dos alunos envolvida em um projeto pedagógico maior, mais duradouro, interdisciplinar e que estabeleça uma conexão entre a escola, o mundo e as realidades atuais.

As pesquisas em Linguística Aplicada voltadas para as questôes de letramento digital em aulas de Língua Portuguesa têm trazido, principalmente, uma realidade teórica com destaque para os aspectos mais linguísticos stricto sensu, desconsiderando as situações de sala de aula - que dialogam com contextos e saberes extraescolares - e silenciando possibilidades de diálogos com outras áreas de conhecimento que podem contribuir para a melhor compreensão deste contexto de ensino-aprendizagem.

\section{Das "pesquisas de intervenção"}

Analisando o conjunto de teses e dissertaçōes e posteriormente, de forma mais detida, as 29 selecionadas, fomos constatando que o conceito de pesquisa de intervenção devesse talvez ser compreendido de forma ampliada, 
como mediação, a fim de melhor contribuir para a interpretação da particular situação constatada por nosso recorte. Os trabalhos de efetiva intervenção no cotidiano escolar existiam, mas eram poucos. Ao mesmo tempo, verificamos a presença de um conjunto de trabalhos que dialogavam diretamente com o espaço da sala de aula de Língua Portuguesa, ainda que se configurassem muito mais como estudos de caso e/ou análises do que pesquisas de intervenção.

Ao comentar o agir do professor no âmbito da teoria e prática, Barros (2012) reforça a importância das pesquisas articuladas a processos de intervenção em espaço da aula.

[N]ão dá para falarmos em uma dicotomia entre teoria e prática quando o foco é o agir do professor. A profissão docente requer uma articulação constante entre todas as instâncias do saber, e é desse próprio agir que "novos" saberes emergem. Por isso, a necessidade constante de pesquisas que foquem a sala de aula, seja do ponto de vista colaborativo ou da pesquisa-ação. (BARROS, 2012, f. 259, grifo nosso).

Confrontando a aplicação da Linguística com a Linguística Aplicada, Widdowson (2000) identifica a intervenção como o ponto em comum entre elas. Porém, enquanto na Linguística a intervenção caracteriza-se pela aplicação direta e unilateral de conceitos e termos com origem na pesquisa linguísticasoluções linguísticas para problemas linguísticos -, na Linguística Aplicada a intervenção deve ser vista essencialmente como mediação. Neste último caso, busca-se conciliar e relacionar, num processo multilateral, diferentes representações da realidade. Os aspectos linguísticos também são contemplados, mas outras representações não devem ser desconsideradas.

Para além da visão didática de reflexão autônoma que coloca em relação as problemáticas da elaboração, apropriação e intervenção, Pereira (2006) entende que, no âmbito da Linguística Aplicada, a intervenção não deva ser tratada de forma isolada em relação às demais problemáticas. Ela compreende a intervenção não como uma simples etapa, mas como um conjunto de questões inseridas em um quadro de situações de ensino-aprendizagem, cuja complexidade não pode ser minimizada.

O fato de identificarmos a dimensão mediadora numa pesquisa de intervenção não significa que adotemos aqui o viés sócio-histórico da pesquisa mediadora, que "consiste numa ação de investigação dialética de caso, que visa, por meio de processos analíticos, transformar a concepção de um objeto do conhecimento dos educandos de uma visão sincrética para uma visão sintética” (RAUEN, 2003, p. 536). Na utilização do conceito de pesquisas de 
intervenção como critério para seleção das teses e dissertações, portanto, limitamo-nos a destacar o seu diálogo mais amplificado, e não menos complexo, com o universo do ensino-aprendizagem de Língua Portuguesa.

Nesse sentido, contribui sobremaneira para os nossos encaminhamentos metodológicos e de análise a dimensão amplificada e articulada de pesquisa de intervenção apresentada por Moita Lopes (1996). Esse pesquisador entende que a pesquisa de intervenção investiga a possibilidade de se modificar a situação existente em sala de aula e tende para a pesquisa qualitativa, notadamente de natureza etnográfica - de descrição narrativa da vida diária da sala de aula a partir de observação participante, diários, entrevistas, gravações de aulas. Volta-se para os processos sociointeracionais envolvidos na construção do conhecimento, com foco no processo de uso da linguagem.

Dentre as teses e dissertações analisadas, há uma série delas que não são exatamente "de intervenção", mas fornecem elementos fundamentais para o trabalho com leitura e produção de hipertextos (T15, por exemplo). Aliás, os aspectos metodológicos que poderiam melhor esclarecer e nortear as ações investigativas das pesquisas, muitas vezes, são tratados de forma quase burocrática, sem maiores aprofundamentos, o que talvez colabore para um perfil de "intervenções" não só heterogêneas como etéreas, que dificultaram uma melhor caracterização desse conjunto.

Ao analisarmos os capítulos metodológicos das teses e dissertações, constatamos pesquisas que não se empenharam em aprofundamentos conceituais de caráter metodológico. Nesse sentido, a maior parte das pesquisas analisadas se apresenta como "qualitativa", de caráter "etnográfico" ou "empírico", enfocando "estudos de caso" ou "pesquisa-ação", sem maiores problematizaçôes dessas metodologias. Os procedimentos e instrumentos metodológicos, no entanto, costumam ser ampla e detalhadamente explicitados. Esse cuidado com os procedimentos e instrumentos metodológicos qualifica sobremaneira as pesquisas com o perfil.

Esperava-se que essas teses e dissertações construíssem um conjunto de possibilidades de intervenções que pudessem ser usadas por professores em suas aulas ou atividades pedagógicas, servindo como uma orientação, mesmo que parcial, para que os professores tivessem um direcionamento em relação ao uso das NTIC como ferramenta pedagógica, contribuindo, assim, para o desenvolvimento de habilidades que colaborariam para o letramento digital dos alunos. Seria ideal que essas teses e dissertações, ao serem analisadas no todo, pudessem revelar um conjunto de princípios, sugestóes ou direcionamentos para o uso das NTIC em ambientes educacionais. 
Essas reflexões de caráter metodológico assinalam um importante flanco a ser mais e melhor trabalhado nas pesquisas em Linguística Aplicada voltadas para questóes de letramento digital e ensino de Língua Portuguesa.

\section{Considerações finais}

As concepções de linguagem de caráter sociointeracionista são imprescindíveis na fundamentação das reflexões relativas aos processos de letramento digital relacionados ao ensino de Língua Portuguesa. Porém, para além das concepções de linguagem, os desafios sinalizados à formação escolar trazidos pela cibercultura tensionam também as concepções de aprendizagem e, ao mesmo tempo, inserem elementos renovados tanto nas concepções de linguagem quanto nas de aprendizagem, como interatividade, autoria, mediação docente, construção do conhecimento, dentre outros aspectos.

As teses e dissertações sobre o tema, produzidas na última década, constituem uma relevante e necessária aproximação do campo de Letras e Linguística às questões atinentes ao letramento digital, não obstante as históricas e reconhecidas dificuldades, tanto no âmbito acadêmico mais amplo quanto especificamente na formação de professores de Língua Portuguesa, em transitar nos meandros cotidianos da "cultura midiática" (KELLNER, 2001). Em diálogo, portanto, com essa produção acadêmica, cumpre-nos agora, na condição de linguistas aplicados, darmos o próximo passo, desenvolvendo pesquisas de intervenção em aulas de Língua Portuguesa que contribuam não só para o trabalho com o letramento digital em Língua Portuguesa na educação básica, mas que também sirvam na constituição de um conjunto de fundamentações e procedimentos metodológicos a alimentar outras pesquisas e intervenções voltadas para o assunto.

\section{Referências}

ANDREOTTI, V.; SOUZA, L. M. T. M. (Org.). Postcolonial Perspectives in Global Citizenship Education. London: Routledge, 2011.

ANPOLL. Lista dos Grupos de Trabalho (GTs) - Linguagem e Tecnologias. 2010. Disponível em: <http://www.anpoll.org.br/portal/gts/\#>. Acesso em: 31 jul. 2013. BARROS, E. M. D. Gestos de ensinar e de aprender gêneros textuais: a sequência didática como instrumento de mediação. 2012. 366 f. Tese (Doutorado em Estudos da Linguagem) - Centro de Letras e Ciências Humanas, Universidade Estadual de Londrina, Londrina, 2012. 
BAZERMAN, C. Gênero, agência e escrita. São Paulo: Cortez, 2006.

BRUNS, A. Blogs, Wikipedia, Second Life, and beyond: From Production to Produsage. New York: Peter Lang, 2008.

BUZATO, M. E. K. Entre a fronteira e a periferia: linguagem e letramento na inclusão digital. 2007. 284 f. Tese (Doutorado em Linguística Aplicada) Instituto de Estudos da Linguagem, Universidade Estadual de Campinas, Campinas, 2007.

CASTRO, G. C.; ALMEIDA, A. Um abismo digital em sala de aula. Correio Braziliense, Brasília, 28 set. 2012. Disponível em: <http://www.correiobraziliense. com.br/app/noticia/eu-estudante/ensino_educacaobasica/2012/09/28/ensino_ educacaobasica_interna,325047/um-abismo-digital-em-sala-de-aula.shtml>. Acesso em: 31 jul. 2013.

COPE, B.; KALANTZIS, M. (Ed.). Multiliteracies: Literacy Learning and the Design of Social Futures. London: Routledge, 2000.

GEE, J. P. Bons videogames e boa aprendizagem. Perspectiva, Florianópolis, v. 27, n. 1, p. 167-178, jan.-jun. 2009.

GERALDI, J. W. Concepções de linguagem e ensino de Português. In: O texto na sala de aula: leitura e produção. Cascavel: Assoeste, 1984. p. 41-49. (Org.).

KELLNER, D. A cultura da mídia: estudos culturais - identidade e política entre o moderno e o pós-moderno. Bauru: Edusc, 2001.

KRESS, G.; VAN LEEUWEN, T. Reading Images: The Grammar of Visual Design. London: Routledge, 1996.

MAFRA, N. D. F.; MOREIRA, V. Letramento digital e formação docente. In: GONÇALVES, A. V.; PETRONI, M. R. (Org.). Formação de professores: o múltiplo e o complexo. Dourados: Editora UFGD, 2012. p. 193-219.

MOITA LOPES, L. P. Oficina de Linguistica Aplicada. Campinas: Mercado de Letras, 1996.

NEW LONDON GROUP. A Pedagogy of Multiliteracies: Designing Social Futures. Harvard Educational Review, v. 66, n. 1, p. 60-92, Spring 1996. Disponível em: <http://mullins-teaching-notebook.wikispaces.com/file/view/ newlondon+pedagogy+of+multiliteracies.pdf $>$. Acesso em: 31 jul. 2013.

PEREIRA, A. D. A. A intervenção didática em uma abordagem interacional de ensino-aprendizagem da língua materna: os percursos de uma pesquisa. Letra Magna, ano 3, n. 5, 2006. Disponível em: <http://www.letramagna.com/ intervencao.pdf>. Acesso em: 31 jul. 2013.

PRIMO, A. Interação mediada por computador: comunicação, cibercultura, cognição. Porto Alegre: Sulina, 2007. 
RAUEN, F. J. Pesquisa mediadora: alternativa metodológica para desenhos de intervenção dialética em Linguística Aplicada. In: ENCONTRO DO CELSUL - CENTRO DE ESTUDOS LINGUÍSTICOS DO SUL, 5., 2003, Curitiba. Anais... Curitiba: Celsul, 2003. p. 536-542. Disponível em: <http:// www.celsul.org.br/Encontros/05/pdf/073.pdf>. Acesso em: 31 jul. 2013.

ROJO, R. Letramentos múltiplos, escola e inclusão social. São Paulo: Parábola, 2009. ROJO, R. Modelização didática e planejamento: duas práticas esquecidas do professor? In: KLEIMAN, A. B. (Org.). A formação do professor: perspectivas da Linguística Aplicada. Campinas: Mercado de Letras, 2008. p. 313-335.

SILVA, M. Sala de aula interativa. 3. ed. Rio de Janeiro: Quartet, 2002.

SOARES, M. Concepções de linguagem e o ensino da língua portuguesa. In: BASTOS, N. B. (Org.). Lingua portuguesa: história, perspectivas, ensino. São Paulo: EDUC, 1998. p. 53-60.

STREET, B. V. Literacy in Theory and Practice. Cambridge (MA): Cambridge University Press, 1984.

STREET, B. V. Os novos estudos sobre o letramento: histórico e perspectivas. In: MARINHO, M.; CARVALHO, G. T. (Org.). Cultura escrita e letramento. Belo Horizonte: Editora UFMG, 2010. p. 33-53.

TRAVAGLIA, L. C. Gramática e interação: uma proposta para o ensino de gramática no $1^{\circ}$ e $2^{\circ}$ graus. São Paulo: Cortez, 1996.

WIDDOWSON, H. G. On the Limitations of Linguistics Applied. Applied Linguistics, v. 21, n. 1, p. 3-25, 2000. Disponível em: <http://www.corpus4u.org/ forum/upload/forum/2005060405544367.pdf>. Acesso em: 31 jul. 2013.

Recebido em 18/12/2012. Aprovado em 17/06/2013. 